Article

\title{
Excellent Temperature-Control Based on Reversible Thermochromic Materials for Light-Driven Phase Change Materials System
}

\author{
Caixia Ren ${ }^{1}$, Fangfang Liu ${ }^{1}$, Malik Muhammad Umair ${ }^{1}{ }^{\mathbb{D}}$, Xin Jin ${ }^{2}$, Shufen Zhang ${ }^{1}$ \\ and Bingtao Tang $1,2, *(\mathbb{D})$ \\ 1 State Key Laboratory of Fine Chemicals, Dalian University of Technology, Dalian 116024, China; \\ 13127037258@163.com (C.R.); liufangfang@mail.dlut.edu.cn (F.L.); umairdut@mail.dlut.edu.cn (M.M.U.); \\ zhangshf@dlut.edu.cn (S.Z.) \\ 2 Eco-chemical Engineering Cooperative Innovation Center of Shandong, Qingdao University of Science and \\ Technology, Qingdao 266042, China; jinx1971@163.com \\ * Correspondence: tangbt@dlut.edu.cn; Tel./Fax: +86-411-8498-6464
}

Academic Editor: Ana Ines Fernandez Renna

Received: 28 February 2019; Accepted: 23 April 2019; Published: 24 April 2019

\begin{abstract}
Light-driven phase change materials (PCMs) have received significant attention due to their capacity to convert visible light into thermal energy, storing it as latent heat. However, continuous photo-thermal conversion can cause the PCMs to reach high thermal equilibrium temperatures after phase transition. In our study, a novel light-driven phase change material system with temperature-control properties was constructed using a thermochromic compound. Thermochromic phase change materials (TC-PCMs) were prepared by introducing 2-anilino-6dibutylamino-3-methylfluoran (ODB-2) and bisphenol A (BPA) into 1-hexadecanol (1-HD) in various proportions. Photo-thermal conversion performance was investigated with solar radiation (low power of $0.09 \mathrm{~W} / \mathrm{cm}^{2}$ ) and a xenon lamp (at a high power of $0.14 \mathrm{~W} / \mathrm{cm}^{2}$ ). The TC-PCMs showed a low equilibrium temperature due to variations in absorbance. Specifically, the temperature of TC-PCM ${ }_{180}$ (ODB-2, bisphenol A and 1-HD ratio 1:2:180) could stabilize at $54{ }^{\circ} \mathrm{C}$ approximately. TC-PCMs exhibited reversibility and repeatability after 20 irradiation and cooling cycles.
\end{abstract}

Keywords: photo-thermal conversion; phase change materials; thermochromic compound; temperature control

\section{Introduction}

As a fossil fuel substitute, solar energy is a renewable and clean alternative energy resource [1,2]. Solar energy utilization-including thermal utilization, photovoltaic conversion and photo-thermal conversion technology-has increasingly advanced [3-7]. However, thermal utilization of solar energy suffers from inferior direct heat usage factors due to inefficient utilization of visible light, which accounts for $44 \%$ of solar radiation [8,9]. To solve this problem, investigators have introduced light harvesting materials (such as dye, carbon materials and metal, etc.) into phase change material systems to obtain high photo-thermal conversion and energy storage efficiency [10-14]. On the other hand, continuous photo-thermal conversion can lead to high thermal equilibrium temperatures of phase change materials (PCMs) after phase transition [15-17]. This critical issue can have certain implications on the application of PCM systems based on photo-thermal conversion materials in some fields.

Typically, in a photo-thermal conversion system, light-harvesting materials absorb visible light, causing valence electrons to jump into an excited state and then deexcite to the ground state mainly by means of non-radiative transition [18,19]. Vast heat energy is emitted and then stored by PCMs [20]. 
In the process, as light radiates unremittingly, the temperature of PCM systems rises due to energy conversion until thermal equilibrium is attained. In a sense, the thermal equilibrium temperature depends on the balance between the photo-thermal conversion rate and heat conduction rate. Fortunately, thermochromic materials, which are typically composed of color former, developer and solvent, show superior performances in temperature control [21,22]. The tendency of thermochromic materials to become colorless and lose light absorption capacity with increases in temperature enables them to achieve quick thermal equilibrium at a low temperature. At present, thermochromism-induced methods of PCM-based systems have been studied widely to achieve energy storage or temperature control [23-26]. Peng Tang et al. designed thermochromism-induced temperature self-regulation and alternating photothermal nanohelix clusters, and applied these to synergistic chemo/phototherma therapy for tumours [26].

In the present study, 2-anilino-6-dibutylamino-3-methylfluoran (ODB-2) was selected as a color former. 1-hexadecanol (1-HD) and bisphenol A (BPA) served as solvent and developer, respectively. The thermochromic materials were black at room temperature, and when 1-hexadecanol melted into an amorphous state, the color faded. This process caused notable light absorption changes due to the color variation of ODB-2, and the thermal equilibrium under irradiation was achieved at a lower temperature, which was beneficial for increasing the photostability of the light-harvesting molecules under continuous irradiation. The mechanism is as follows: ODB-2, like many other similar chromophores, presents two different isomers: the leuco lactone form, which is colorless, and the open carboxylate state, which is colored. When 1-HD starts to crystalize as temperature decreases, the equilibrium between both isomers of ODB-2 is displaced by interactions with bisphenol A through hydrogen bonding, which favors ring-opening of the color former (Figure 1) [27-30].

In this work, thermochromic phase change materials (TC-PCMs) were obtained via combining ODB-2 and BPA with 1-HD in various ratios. Then, the photo-thermal conversion property was evaluated under different light sources: solar radiation (low power approximately $0.09 \mathrm{~W} / \mathrm{cm}^{2}$ ) and xenon lamp (high power approximately $0.14 \mathrm{~W} / \mathrm{cm}^{2}$ ). A similar trend was observed in both conditions: temperature can be controlled at a certain range. After 20 irradiation and cooling cycles, temperature control properties of TC-PCMs was found to be still achievable.

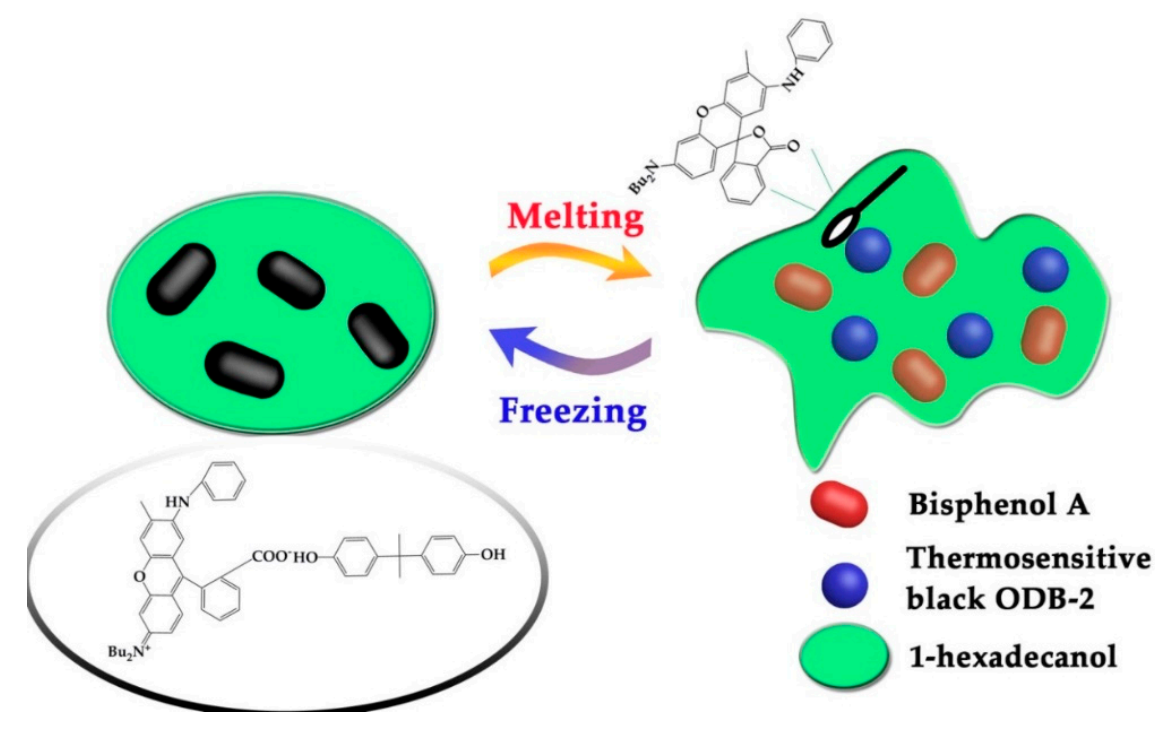

Figure 1. Diagram of the thermochromic process. 


\section{Results and Discussion}

\subsection{FT-IR Analysis}

Figure 2 shows the Fourier Transform Infrared (FT-IR) spectra of 1-HD and TC-PCMs. The characteristic peak of $\mathrm{COO}^{-}$at $1607 \mathrm{~cm}^{-1}$ attributed to the addition of thermochromic compound [31], appeared in all TC-PCMs' curves. It confirmed the ring-opening structure of the lactone ring in ODB-2. Furthermore, the peaks at $3303 \mathrm{~cm}^{-1}$ (stretching vibration of O-H), $2956 \mathrm{~cm}^{-1}$ (C-H stretching vibration of $\left.-\mathrm{CH}_{3}\right), 2850 \mathrm{~cm}^{-1}\left(\mathrm{C}-\mathrm{H}\right.$ stretching vibrations of $\left.-\mathrm{CH}_{2}\right)$ and $1062 \mathrm{~cm}^{-1}$ (C-O stretching vibration) are typical of 1-HD.

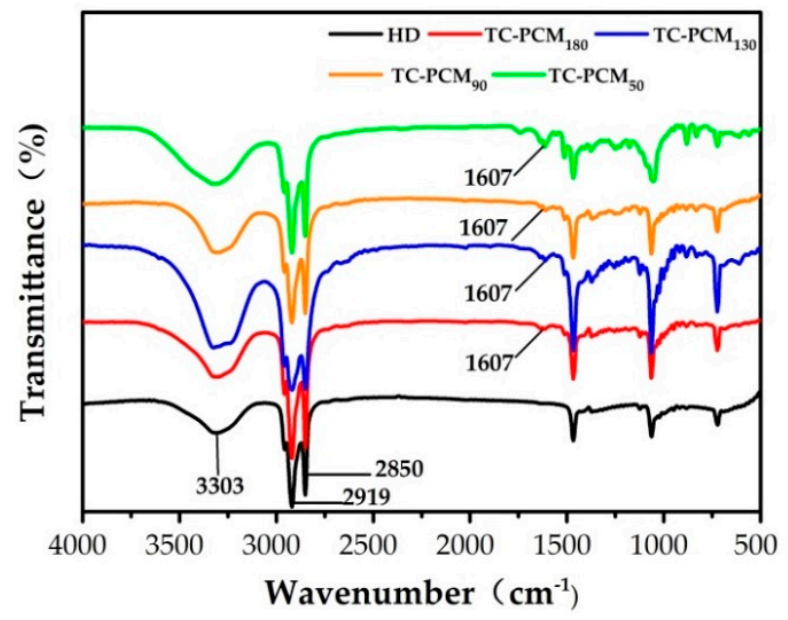

Figure 2. FT-IR spectra of 1-hexadedocanol (1-HD), thermochromic phase change material TC-PCM 180 , TC-PCM 130, TC-PCM 90 and TC-PCM 50.

\subsection{Thermal Property of TC-PCMs}

Phase transition temperature and enthalpy play important roles in measuring the energy-storage performances of PCMs, which were characterized by differential scanning calorimetry (DSC). Figure 3 and Table 1 show the DSC curves and specific data on TC-PCMs, respectively. The 1-HD curve featured two exothermic peaks, which were caused by solid-solid transition at $42{ }^{\circ} \mathrm{C}$ (forming a rotation phase) [32] and liquid-solid transition at $48^{\circ} \mathrm{C}$, and an endothermic peak overlapped by two transitions (as mentioned above) [33]. The melting point $\left(\mathrm{T}_{\mathrm{m}}\right.$ ) of 1 - $\mathrm{HD}$ was $48.76{ }^{\circ} \mathrm{C}$, and the cooling points including liquid-solid transition $\left(\mathrm{T}_{\mathrm{C}}\right)$ and solid-solid transition $\left(\mathrm{T}_{\mathrm{t}}\right)$ were $48^{\circ} \mathrm{C}$ and $41.87^{\circ} \mathrm{C}$, respectively.

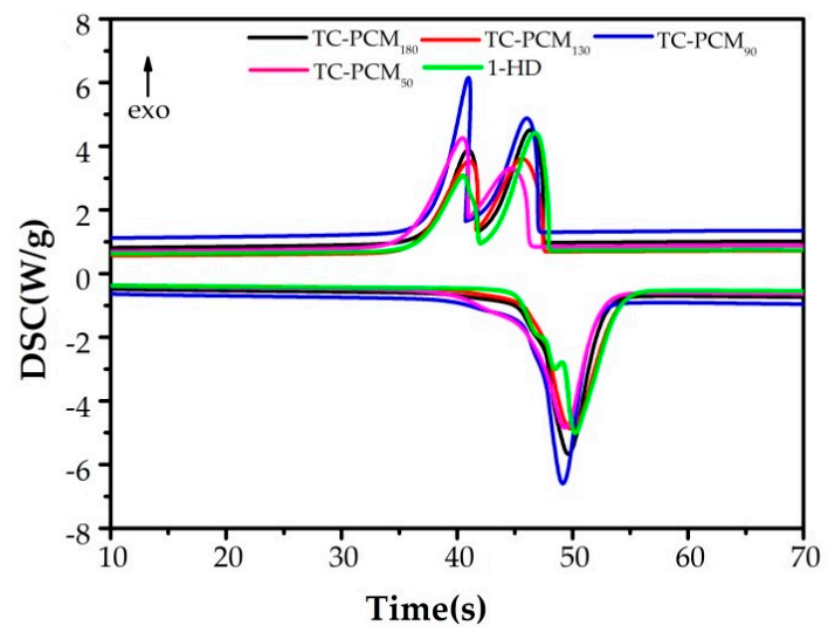

Figure 3. Curves of TC-PCM 180, TC-PCM 130, TC-PCM 90, TC-PCM $\mathrm{P}_{50}$, and pure 1-HD. 
The phase transition temperatures $\left(\mathrm{T}_{\mathrm{c}}\right.$ and $\left.\mathrm{T}_{\mathrm{m}}\right)$ of TC-PCMs decreased subtly with increasing doping amounts (mass fraction of ODB-2 and BPA). Contrary to this, enthalpy values increase to varying degrees. This result can be attributed to the addition of a thermochromic compound, which promoted the formation of the rotator phase and crystalline structure of 1-HD [28]. Therefore, appropriate addition of ODB-2 and BPA had a negligible effect on the phase transition temperature and enhanced the enthalpy values of TC-PCMs.

Table 1. Thermal date of TC-PCMs and pure 1-HD.

\begin{tabular}{ccccccc}
\hline Sample & $\mathbf{T C}(\mathbf{\%} \mathbf{w t})$ & $\mathbf{T}_{\mathbf{c}}\left({ }^{\circ} \mathbf{C}\right)$ & $\mathbf{T}_{\mathbf{t}}\left({ }^{\circ} \mathbf{C}\right)$ & $\Delta \mathbf{H}_{\mathbf{c}}(\mathbf{J} / \mathbf{g})$ & $\mathbf{T}_{\mathbf{m}}\left({ }^{\circ} \mathbf{C}\right)$ & $\Delta \mathbf{H}_{\mathbf{m}}(\mathbf{J} / \mathbf{g})$ \\
\hline 1-HD & 0.00 & 48.00 & 41.87 & 229.5 & 48.76 & 233.8 \\
TC-PCM $_{30}$ & 1.89 & 46.23 & 41.12 & 242.9 & 46.04 & 244.5 \\
TC-PCM $_{90}$ & 1.08 & 47.01 & 40.81 & 244.9 & 46.95 & 240.3 \\
TC-PCM $_{130}$ & 0.75 & 47.47 & 41.85 & 248.9 & 47.03 & 247.2 \\
TC-PCM $_{180}$ & 0.55 & 47.45 & 41.81 & 236.3 & 47.13 & 238.7 \\
\hline
\end{tabular}

\subsection{X-ray Diffraction (XRD) Analysis}

The crystallization property was characterized by X-ray Diffraction (XRD). As shown in curve a of Figure 4, typical diffraction peaks of 1-HD were observed at angles of $2 \theta=20.6^{\circ}, 21.4^{\circ}, 21.8^{\circ}$, $22.1^{\circ}, 24.2^{\circ}, 24.7^{\circ}$, which corresponded to the TC-PCMs. In curves $\mathrm{c}-\mathrm{e}$, the peaks at $21.4^{\circ}$ and $24.2^{\circ}$ weakened - probably due to the doping of dyes. In curve b, the diffraction peaks were nearly unchanged, indicating that the doping dose of TC-PCM 180 had no significant influence on the crystallinity of 1-HD.

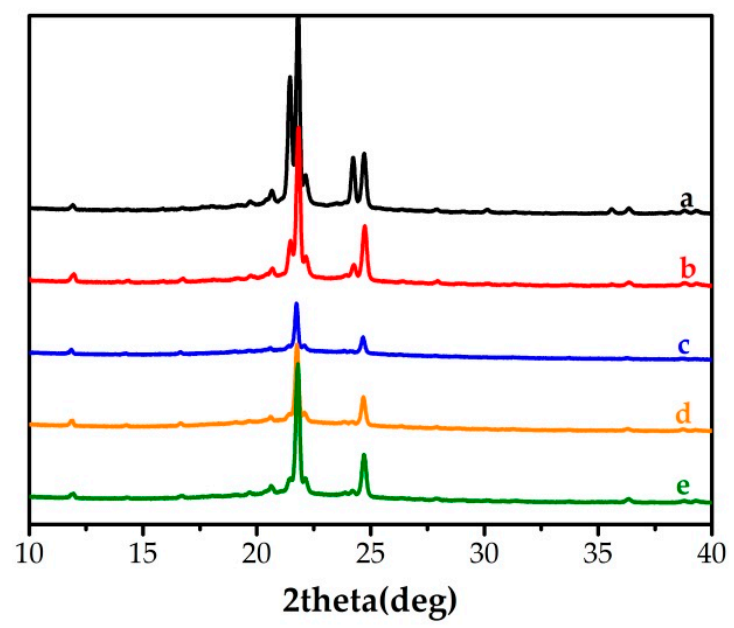

Figure 4. X-ray Diffraction (XRD) patterns of (a) 1-HD, (b) TC-PCM 180 , (c) TC-PCM 130 , (d) TC-PCM90, (e) TC-PCM 50 .

\subsection{Photo-Thermal Conversion Analysis}

To study the temperature-control property of thermochromic materials, photo-thermal conversion was tested (Figure 5). Figure 5a,b shows the photo-thermal conversion curves of TC-PCMs and $\mathrm{CB}_{180}$. In Figure $5 \mathrm{a}$, under sunlight irradiation $\left(0.09 \mathrm{~W} / \mathrm{cm}^{2}\right)$, the thermal equilibrium temperature of TC-PCMs was evidently lower than that of $\mathrm{CB}_{180}$. This result was due to the structural transformation of the thermochromic compound when the temperature was higher than the phase transition temperature of 1-HD (Figure 5d) [22,33]. Furthermore, the thermal equilibrium temperature of TC-PCM 180 stabilized at $56{ }^{\circ} \mathrm{C}$ in contrast with that of $\mathrm{CB}_{180}$, whose temperature exceeded $64{ }^{\circ} \mathrm{C}$. Figure $5 \mathrm{~b}$ shows the curves of TC-PCMs under the higher power of a simulative light source (IR removal, approximately $0.14 \mathrm{~W} / \mathrm{cm}^{2}$ ). The same tendency was exhibited: TC-PCMs achieved lower thermal equilibrium temperatures. Therefore, as the lowest TC compound ratio (mass fraction of TC compound, $1.63 \%$ ), TC-PCM 180 
can attain lower thermal equilibrium temperatures under high or low irradiating power. This result indicates that TC-PCM 180 exhibits good temperature-control property for photo-thermal conversion.

In order to further investigate the temperature-control property of different PCMs with thermochromic compound, we selected 1-tetradecanol as the PCM, at an optimum ratio of 1:2:180 (ODB-2: BPA: 1-tetradecanol) under solar irradiation. The results are shown in Figure 5c. The curves of 1-tetradecanol and 1-HD reached different thermal temperatures of $51.5^{\circ} \mathrm{C}$ and $43.4^{\circ} \mathrm{C}$ respectively, which indicated that the system temperature could be controlled under irradiation.
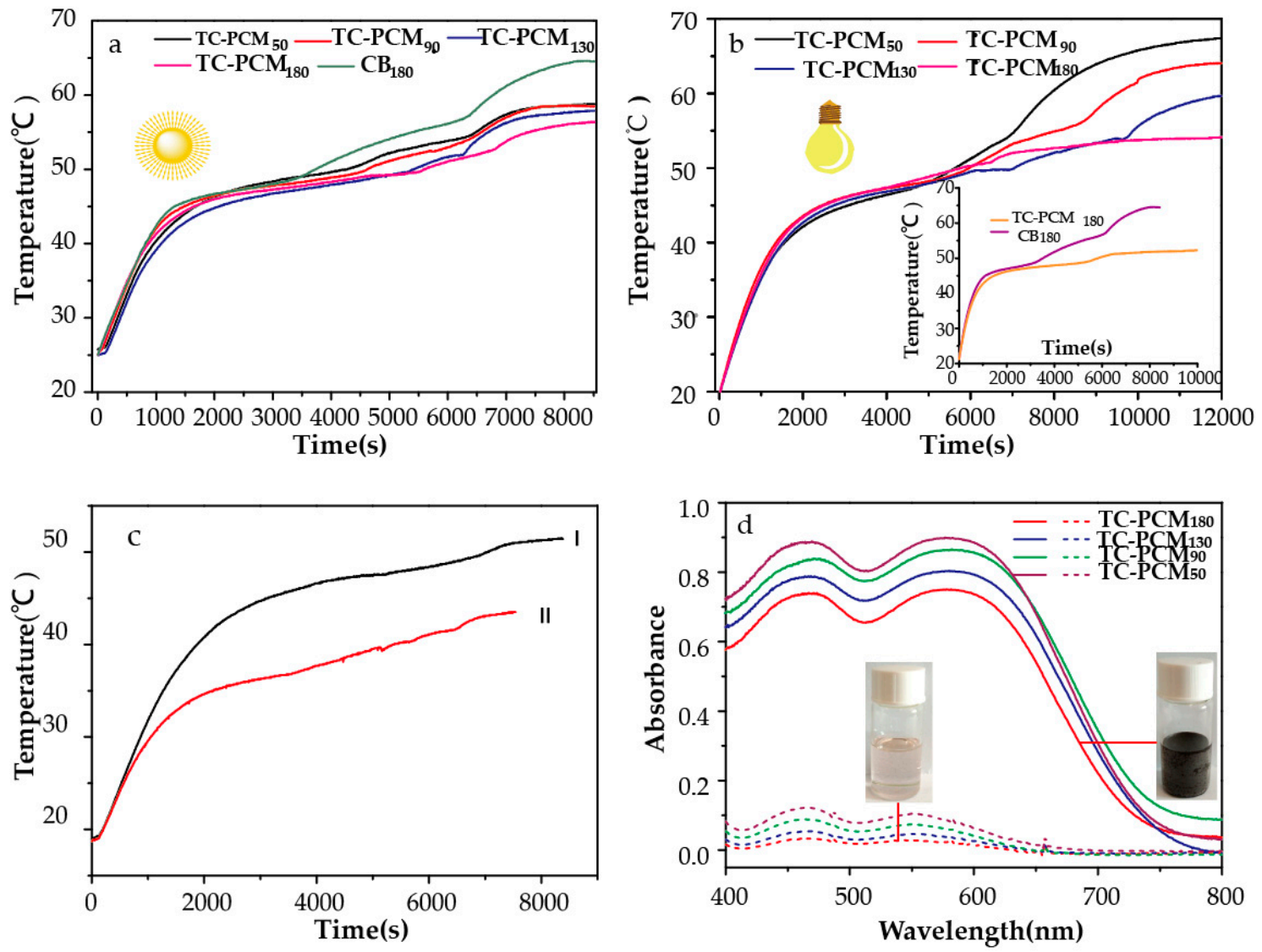

Figure 5. (a) Photo-thermal conversion curves under solar radiation (b) Photo-thermal conversion curves under simulative light (c) Photo-thermal conversion curves of 1-hexadecanol (I) and 1-tetradecanol (II) as PCMs (d) visible light absorption of TC-PCMs under liquid and solid state.

\subsection{Cycle Performance}

The light reversibility and durability of TC-PCMs is a key factor to determine practical application in thermal storage systems. TC-PCMs underwent 20 irradiation and cooling cycles, and the photo-thermal conversion performance before and after cycling test is shown in Figure 6. The curves of TC-PCMs before and after 20 irradiation cycles were essentially consistent. The results indicate that TC-PCMs kept good photo-thermal conversion performance after 20 times cycles. And temperature can be controlled in a certain scope. 

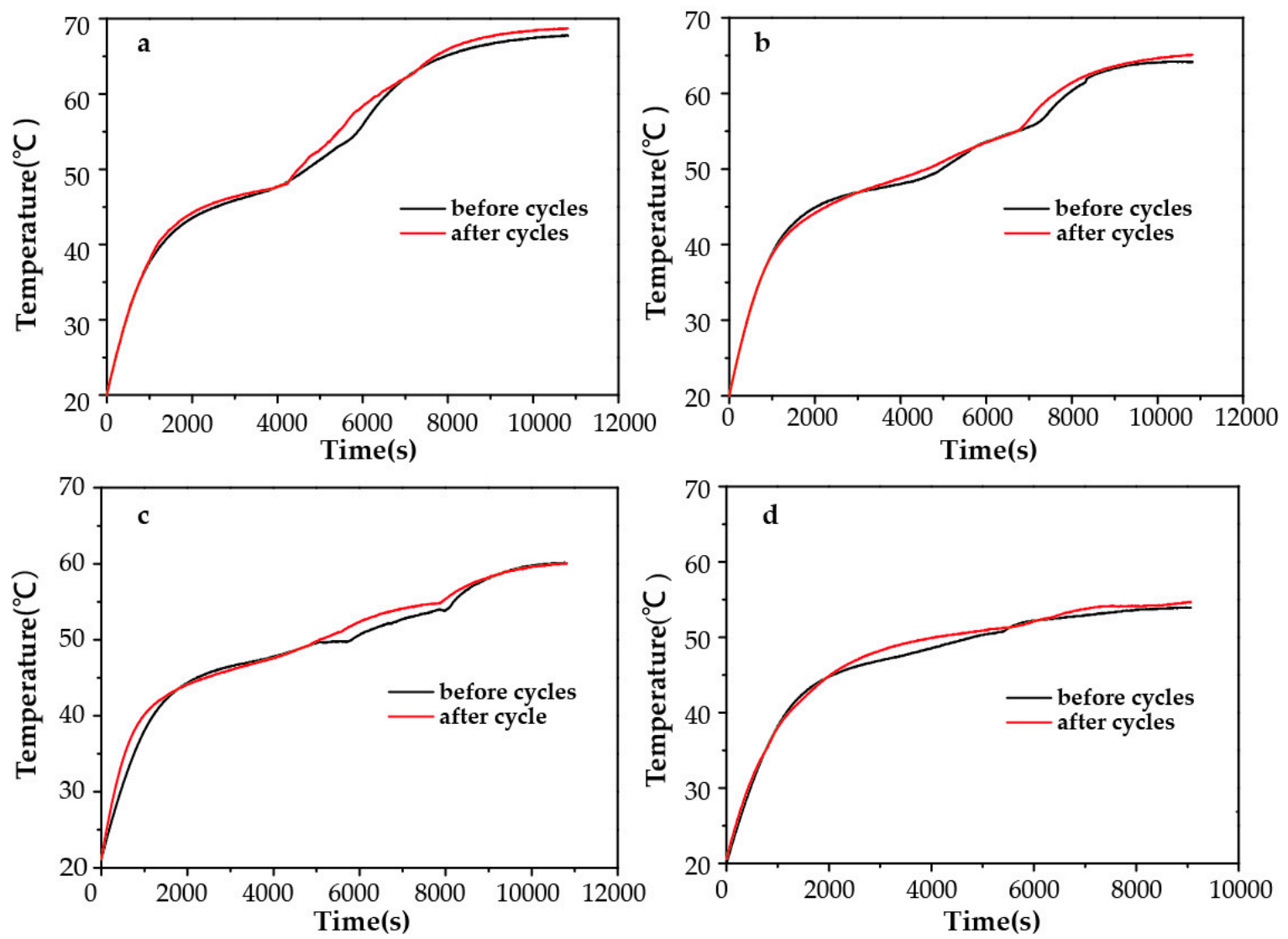

Figure 6. Photo-thermal conversion before and after 20 times irradiation and cooling cycles of (a) TC-PCM ${ }_{50}$ (b) TC-PCM 90 (c) TC-PCM 130 (d) TC-PCM 180 .

\section{Materials and Methods}

\subsection{Materials}

1-Hexadecanol (HD), 1-tertradecanol and bisphenol A (BPA, 2,2-bis(4-hydroxyphenyl)propane) were supplied by Tianjin Damao chemical reagent factory. 1-tertradecanol, 2-Anilino-6dibutylamino-3-methylfluoran (ODB-2) was supplied by Shenzhen Duao science and technology Ltd. (Shenzhen, China). Carbon black purchased from Cabot Corporation (Boston, MA, USA) was modified with diazonium salt to disperse in the oil phase.

\subsection{Preparation of TC-PCMs}

Different ratios of TC-PCMs were obtained by mixing 1-HD, BPA and ODB-2 at weight ratios of 1:2:30, 1:2:60, 1:2:120 and 1:2:180 (TC-PCM 30, TC-PCM 60 , TC- PCM 120 and TC-PCM P $_{180}$, respectively). 1-HD was melted at $80{ }^{\circ} \mathrm{C}$ for $1 \mathrm{~h}$ via oil bath, then BPA and ODB-2 were dissolved in 1-HD with varying percentages in a $185{ }^{\circ} \mathrm{C}$ thermostatic oil bath for $2 \mathrm{~min} . \mathrm{CB}_{180}$ was obtained by replacing ODB-2 with CB (carbon black) in TC-PCM 180 . 1-tertradecanol (replacing 1-hexadecanol at the ratio of 1:2:180) systems were obtained identically.

\subsection{Characterization of TC-PCMs}

FT-IR spectrophotometry (Nicolet 6700, Waltham, MA, USA) was used to evaluate the structure of TC-PCMs and 1-HD (using KBr pearls). The thermal properties of TC-PCMs and 1-HD were measured by DSC (TA Q20, New Castle, Delaware, USA), with a heating rate of $5^{\circ} / \mathrm{min}$ in an $\mathrm{N}_{2}$ atmosphere. The crystallinity of the samples was estimated through XRD (D/Max 2400, Rigaku, Tokyo, Japan) from $10^{\circ}$ to $80^{\circ}$. The UV-visible absorption spectra of solid and liquid TC-PCMs were obtained using a 
Hitachi U-4100 (Tokyo, Japan) spectrophotometer and an Agilent HP 8453 (Santa Clara, CA, USA) spectrophotometer, respectively.

In the photo-thermal conversion property test: both solar radiation and a simulated light (CHF-XM35-500W xenon lamp with a parallel light source system, PerfectLight, Beijing, China) were used as photo sources. The xenon lamp produced light with continuous wavelength, ranging from $200 \mathrm{~nm}$ to $2000 \mathrm{~nm}$, and its energy distribution in the visible light area is similar to those of the solar spectrum. In contrast, near-infrared light $(700 \mathrm{~nm}$ to $1100 \mathrm{~nm})$, which heightens energy distribution vastly, was removed by an IR-CUT filter. The light intensity of sunlight was approximately $0.09 \mathrm{~W} / \mathrm{cm}^{2}$. $0.14 \mathrm{~W} / \mathrm{cm}^{2}$ of simulated light (approaching the strongest amounts of solar radiation) was chosen to study photo-thermal conversion performances under high-intensity light. Meanwhile, the power was measured by an optical power meter (Perfect light PL-MW2000, Beijing, China). The temperature values were automatically recorded using a numerical control thermometer every $4 \mathrm{~s}$.

\section{Conclusions}

In this research, a light-driven PCM system with temperature-control properties was constructed by preparing TC-PCMs. DSC analysis showed a slight shift in phase transition temperature of approximately $1{ }^{\circ} \mathrm{C}$, and enthalpy increased to $247 \mathrm{~J} / \mathrm{kg}$ (in TC-PCM $\mathrm{PM}_{130}$ ). The photo-thermal conversion test demonstrated that the ultimate temperature could be stabilized at specific values as the TC compound turned from black to a tinted shade during the phase change of 1-HD, which caused a drastic decrease in absorbance. With the lowest doping dose and minimum absorbance, TC-PCM 180 reached $54{ }^{\circ} \mathrm{C}$ under a certain power range and exhibited the best temperature-control property. Furthermore, 1-tetradecanol systems were explored at an optimal ratio of 1:2:180, in which temperature can be controlled at the same range. In addition, the reversibility and durability of TC-PCMs remained unchanged after 20 irradiation and cooling cycles. Thus, the temperature-control performance of light-driven PCM systems was explored, and, based on thermochromic theory, excellent energy storage properties were achieved.

Author Contributions: C.R. and B.T. conceived and designed the experiments in the manuscript. C.R. wrote the manuscript; F.L. and M.M.U. were involved in the writing and modification of the manuscript. X.J. and S.Z. were involved in editing the manuscript.

Funding: This research was funded by National Natural Science Foundation of China (21576039, 21878043, 21536002, 21421005 and U1608223), Program for Innovative Research Team in University (IRT_13R06), the Fundamental Research Funds for the Central Universities (DUT18ZD218).

Conflicts of Interest: The authors declare no conflict of interest.

\section{References}

1. Alva, G.; Liu, L.; Huang, X.; Fang, G. Thermal energy storage materials and systems for solar energy applications. Renew. Sust. Energ. Rev. 2017, 68, 693-706. [CrossRef]

2. Zhang, Y.; Gurzadyan, G.G.; Umair, M.M.; Wang, W.; Lu, R.; Zhang, S.; Tang, B. Ultrafast and efficient photothermal conversion for sunlight-driven thermal-electric system. Chem. Eng. J. 2018, 344, 402-409. [CrossRef]

3. Cui, T.; Xuan, Y.; Li, Q. Design of a novel concentrating photovoltaic-thermoelectric system incorporated with phase change materials. Energ. Convers. Manage. 2016, 112, 49-60. [CrossRef]

4. Kapsalis, V.; Karamanis, D. Solar thermal energy storage and heat pumps with phase change materials. Appl. Therm. Eng. 2016, 99, 1212-1224. [CrossRef]

5. Zhang, L.; Li, R.; Tang, B.; Wang, P. Solar-thermal conversion and thermal energy storage of graphene foam-based composites. Nanoscale 2016, 8, 14600-14607. [CrossRef]

6. Wang, W.; Fan, X.; Qiu, J.; Umair, M.M.; Ju, B.; Zhang, S.; Tang, B. Extracorporeal magnetic thermotherapy materials for self-controlled temperature through phase transition. Chem. Eng. J. 2019, 358, 1279-1286. [CrossRef] 
7. Umair, M.M.; Zhang, Y.; Iqbal, K.; Zhang, S.; Tang, B. Novel strategies and supporting materials applied to shape-stabilize organic phase change materials for thermal energy storage-A review. Appl. Energ. 2019, 235, 846-873. [CrossRef]

8. Tahan Latibari, S.; Sadrameli, S.M. Carbon based material included-shaped stabilized phase change materials for sunlight-driven energy conversion and storage: An extensive review. Sol. Energy 2018, 170, 1130-1161. [CrossRef]

9. Wang, Y.; Tang, B.; Zhang, S. Novel organic solar thermal energy storage materials: Efficient visible light-driven reversible solid-liquid phase transition. J. Mater. Chem. 2012, 22, 18145-18150. [CrossRef]

10. Ma, X.; Liu, Y.; Liu, H.; Zhang, L.; Xu, B.; Xiao, F. Fabrication of novel slurry containing graphene oxide-modified microencapsulated phase change material for direct absorption solar collector. Sol. Energ. Mater. Sol. C. 2018, 188, 73-80. [CrossRef]

11. Wang, F.; Ling, Z.; Fang, X.; Zhang, Z. Optimization on the photo-thermal conversion performance of graphite nanoplatelets decorated phase change material emulsions. Sol. Energ. Mater. Sol. C. 2018, 186, 340-348. [CrossRef]

12. Wang, Y.; Tang, B.; Zhang, S. Single-walled carbon nanotube/phase change material composites: Sunlight-driven, reversible, form-stable phase transitions for solar thermal energy storage. Adv. Funct. Mater. 2013, 23, 4354-4360. [CrossRef]

13. Xu, B.; Zhou, J.; Ni, Z.; Zhang, C.; Lu, C. Synthesis of novel microencapsulated phase change materials with copper and copper oxide for solar energy storage and photo-thermal conversion. Sol. Energ. Mater. Sol. C. 2018, 179, 87-94. [CrossRef]

14. Zhang, Y.; Wang, J.; Qiu, J.; Jin, X.; Umair, M.M.; Lu, R.; Zhang, S.; Tang, B. Ag-graphene/PEG composite phase change materials for enhancing solar-thermal energy conversion and storage capacity. Appl. Energ. 2019, 237, 83-90. [CrossRef]

15. Wang, Y.; Tang, B.; Zhang, S. Organic, cross-linking, and shape-stabilized solar thermal energy storage materials: A reversible phase transition driven by broadband visible light. Appl. Energ. 2014, 113, 59-66. [CrossRef]

16. Tang, B.; Wei, H.; Zhao, D.; Zhang, S. Light-heat conversion and thermal conductivity enhancement of PEG/SiO 2 composite pcm by in situ $\mathrm{Ti}_{4} \mathrm{O}_{7}$ doping. Sol. Energ. Mater. Sol. C. 2017, 161, 183-189. [CrossRef]

17. Kim, J.U.; Lee, S.; Kang, S.J.; Kim, T.I. Materials and design of nanostructured broadband light absorbers for advanced light-to-heat conversion. Nanoscale 2018, 10, 21555-21574. [CrossRef]

18. Becker, K.; Lupton, J.M. Efficient light harvesting in dye-endcapped conjugated polymers probed by single molecule spectroscopy. J. Am. Chem. Soc. 2006, 148, 6468-6479. [CrossRef]

19. Wang, H.; Qian, G.; Wang, M.; Zhang, J.; Luo, Y. Enhanced luminescence of an erbium (iii) ion-association ternary complex with a near-infrared dye. J. Phys. Chem. B 2004, 108, 8084-8088. [CrossRef]

20. Ahmed, S.F.; Khalid, M.; Rashmi, W.; Chan, A.; Shahbaz, K. Recent progress in solar thermal energy storage using nanomaterials. Renew. Sust. Energ. Rev. 2017, 67, 450-460. [CrossRef]

21. Zhang, Y.; Hu, Z.; Xiang, H.; Zhai, G.; Zhu, M. Fabrication of visual textile temperature indicators based on reversible thermochromic fibers. Dyes Pigments 2019, 162, 705-711. [CrossRef]

22. Malherbe, I.; Sanderson, R.D.; Smit, E. Reversibly thermochromic micro-fibres by coaxial electrospinning. Polymer 2010, 51, 5037-5043. [CrossRef]

23. Han, G.G.D.; Deru, J.H.; Cho, E.N.; Grossman, J.C. Optically-regulated thermal energy storage in diverse organic phase-change materials. Chem. Comm. 2018, 54, 20722.

24. Han, G.G.D.; Li, H.; Grossman, J.C. Optically-controlled long-term storage and release of thermal energy in phase-change materials. Nat. Commun. 2017, 8, 1446. [CrossRef]

25. Harrington, W.N.; Haji, M.R.; Galanzha, E.I.; Nedosekin, D.A. Photoswitchable non-fluorescent thermochromic dye-nanoparticle hybrid probes. Sci. Rep. 2016, 6, 36417. [CrossRef]

26. Tang, P.; Liu, Y.; Liu, Y.; Meng, H.; Liu, Z.; Li, K.; Wu, D. Thermochromism-induced temperature self-regulation and alternating photothermal nanohelix clusters for synergistic tumor chemo/photothermal therapy. Biomaterials 2019, 188, 12-23. [CrossRef]

27. Zhu, X.; Liu, Y.; Dong, N.; Li, Z. Fabrication and characterization of reversible thermochromic wood veneers. Sci. Rep. 2017, 7, 16933. [CrossRef] 
28. Yang, H.; Wang, Y.; Yu, Q.; Cao, G.; Yang, R.; Ke, J.; Di, X.; Liu, F.; Zhang, W.; Wang, C. Composite phase change materials with good reversible thermochromic ability in delignified wood substrate for thermal energy storage. Appl. Energ. 2018, 212, 455-464. [CrossRef]

29. Carreto, L.; Almeida, A.R.; Fernandes, A.C. Thermotropic mesomorphism of a model system for the plant epicuticular wax layer. Biophys. J. 2002, 82, 530-540. [CrossRef]

30. Geng, X.; Li, W.; Yin, Q.; Wang, Y.; Han, N.; Wang, N.; Bian, J.; Wang, J.; Zhang, X. Design and fabrication of reversible thermochromic microencapsulated phase change materials for thermal energy storage and its antibacterial activity. Energy 2018, 159, 857-869. [CrossRef]

31. Maclaren, D.C.; White, M.A. Design rules for reversible thermochromic mixtures. J. Mater. Sci. 2005, 40, 669-676. [CrossRef]

32. Ventola, L.; Ramírez, M.; Calvet, T.; Solans, X. Polymorphism of n-alkanols: 1-heptadecanol, 1-octadecanol, 1-nonadecanol, and 1-eicosanol. Chem. Mater. 2002, 14, 508-517.

33. Van Miltenburg, J.C.; Oonk, H.A.J. Heat capacities and derived thermodynamic functions of 1-octadecanol, 1-nonadecanol, 1-eicosanol, and 1-docosanol between $10 \mathrm{k}$ and $370 \mathrm{k}$. J. Chem. Eng. Data 2001, 46, 90-97. [CrossRef]

Sample Availability: Samples of the compounds are not available from the authors. 